Article

\title{
Synergistic Antibacterial Effects of Nanoparticles Encapsulated with Scutellaria baicalensis and Pure Chlorhexidine on Oral Bacterial Biofilms
}

\author{
Ken Cham-Fai Leung ${ }^{1,+}$, Chaminda Jayampath Seneviratne ${ }^{2,+}$, Xuan $\mathrm{Li}^{3}$, Ping Chung Leung ${ }^{4}$, \\ Clara Bik San Lau ${ }^{4}$, Chi-Hin Wong ${ }^{1}$, Ka Yan Pang ${ }^{3}$, Chun Wai Wong ${ }^{4}$, Elaine Wat ${ }^{4}$ and \\ Lijian Jin ${ }^{3, *}$ \\ 1 Department of Chemistry, Institute of Creativity, and Partner State Key Laboratory of Environmental and \\ Biological Analysis, The Hong Kong Baptist University, Kowloon, Hong Kong, China; \\ cfleung@hkbu.edu.hk (K.C.-F.L.); hinciwong@gmail.com (C.-H.W.) \\ 2 Faculty of Dentistry, National University of Singapore, 11 Lower Kent Ridge Road, Singapore City 119083, \\ Singapore; chaminda_jayampath@nuhs.edu.sg \\ 3 Faculty of Dentistry, The University of Hong Kong, 34 Hospital Road, Hong Kong, China; \\ lixuanlwj@hotmail.com (X.L.); nisdabendan@gmail.com (K.Y.P.) \\ 4 Institute of Chinese Medicine and Partner State Key Laboratory of Phytochemistry and \\ Plant Resources in West China, The Chinese University of Hong Kong, New Territories, \\ Hong Kong, China; pingcleung@cuhk.edu.hk (P.C.L.); claralau@cuhk.edu.hk (C.B.S.L.); \\ cwwong_eric@cuhk.edu.hk (C.W.W.); elaine.wat@cuhk.edu.hk (E.W.) \\ * Correspondence: ljjin@hku.hk; Tel.: +852-2859-0302 \\ + These two authors contributed equally to this work.
}

Academic Editor: Yoshihiro Ito

Received: 22 January 2016; Accepted: 30 March 2016; Published: 7 April 2016

\begin{abstract}
Scutellaria baicalensis (SB) is a traditional Chinese medicine for treating infectious and inflammatory diseases. Our recent study shows potent antibacterial effects of nanoparticleencapsulated chlorhexidine (Nano-CHX). Herein, we explored the synergistic effects of the nanoparticle-encapsulated SB (Nano-SB) and Nano-CHX on oral bacterial biofilms. Loading efficiency of Nano-SB was determined by thermogravimetric analysis, and its releasing profile was assessed by high-performance liquid chromatographyusing baicalin (a flavonoid compound of SB) as the marker. The mucosal diffusion assay on Nano-SB was undertaken in a porcine model. The antibacterial effects of the mixed nanoparticles (Nano-MIX) of Nano-SB and Nano-CHX at 9:1 $(w / w)$ ratio were analyzed in both planktonic and biofilm modes of representative oral bacteria. The Nano-MIX was effective on the mono-species biofilms of Streptococcus (S.) mutans, S. sobrinus, Fusobacterium (F.) nucleatum, and Aggregatibacter (A.) actinomycetemcomitans (MIC $50 \mu \mathrm{g} / \mathrm{mL}$ ) at $24 \mathrm{~h}$, and exhibited an enhanced effect against the multi-species biofilms such as S. mutans, F. nucleatum, A. actinomycetemcomitans, and Porphyromonas (P.) gingivalis (MIC $12.5 \mu \mathrm{g} / \mathrm{mL}$ ) at $24 \mathrm{~h}$ that was supported by the findings of both scanning electron microscopy (SEM) and confocal scanning laser microscopy (CLSM). This study shows enhanced synergistic antibacterial effects of the Nano-MIX on common oral bacterial biofilms, which could be potentially developed as a novel antimicrobial agent for clinical oral/periodontal care.
\end{abstract}

Keywords: nanotechnology; Scutellaria baicalensis; traditional Chinese medicine; chlorhexidine; oral biofilms; antimicrobials

\section{Introduction}

Periodontal disease is a major global oral health burden and severe periodontitis accounts primarily for multiple tooth loss in the adult population worldwide [1,2]. It badly affects oral health and also significantly links with systemic diseases such as diabetes mellitus and cardiovascular 
disease [2,3]. Periodontal disease results from aberrant and exaggerated immuno-inflammatory response to pathogenic plaque biofilms [4]. Therefore, various anti-biofilm and host modulatory therapy have been tested for controlling periodontal disease [5]. Chlorhexidine (CHX) has long been recognized as the golden standard of chemical plaque control for oral healthcare products. CHX gluconate-containing mouthwash is a common chemical plaque control measure [6]. However, there are certain side effects associated with CHX containing mouthwash, such as staining on the teeth, unpleasant taste, allergic reactions, and occasionally numbness of the tongue [7,8]. In addition, $\mathrm{CHX}$ is a classical disinfectant agent which kills all the bacteria without discriminating harmful pathogens. It might also be toxic to the host cells [9]. This caveat has prompted researchers to look into alternative anti-biofilm and host modulating agents and approaches.

Scutellaria baicalensis (SB) is a traditional Chinese medicine frequently used for treating infectious and inflammatory diseases for thousands of years [10]. Chinese literature reports that it has been used to manage periodontal disease [11]. Previous studies have confirmed that baicalin, a flavonoid compound isolated from SB, possesses marked anti-inflammatory, antioxidative, and immunomodulating effects [12-15]. It exhibits protective effect on the development of experimental periodontitis [12] and benefits for controlling periodontal disease $[13,16]$. We have further shown that baicalin could modulate $P$. gingivalis lipopolysaccharide-induced immuno-inflammatory response in oral epithelia [14]. Interestingly, recent studies indicate that SB has potent antibacterial effects on oral pathogens [17], and it could indeed inhibit bacterial quorum sensing activity [18]. A recent study indicates that the combined use of another compound baicalein present in SB with antibiotics has synergistic effects against oral bacteria [19].

Nano-encapsulation technique has currently become an exciting new approach to the delivery of biologically active compounds and agents more effectively at specific biological niches [20,21]. Hence, nanotechnology has received great attention for developing new healthcare products and drugs [22]. Recently, our team has successfully synthesized a novel mesoporous silica nanoparticle (MSN)-encapsulated chlorhexidine (Nano-CHX), which demonstrates potent antibacterial effects on oral biofilms [23]. It has also been shown that nanoparticle-encapsulated plant extracts enhance the biological effectiveness via bioavailability and fast penetration with less cytotoxicity, reduced dosage of the agents, and low costs [24]. Currently, nanotechnology has been increasingly applied in biomedical research and development of novel drug delivery systems. Therefore, nano-encapsulated Chinese herbal extracts or active compounds could enhance their biological effectiveness.

It has been well documented that oral mucosa serves as an attractive and preferred route for systemic delivery of drugs, due to its featured biological structure, easy accessibility, high acceptance by patients [25]. Compared to the skin, the buccal mucosa is far more permeable [26,27], which makes it an instrumental and feasible approach to screening new drugs, assessing drug delivery efficacy, bioavailability, and underlying mechanisms of drug transport as well as refining transbuccal drug delivery. The Franz-Type Diffusion Cells model using porcine oral mucosa has been employed for assay of drug diffusion and absorption [28]. With the similarity in membrane morphology, biological structure and contents, and permeability barrier properties between human and porcine skins and buccal mucosas, this ex vivo model has been well employed on investigation of the feasibility of drug delivery and the underlying drug transport mechanism $[29,30]$.

In the present study, we comprehensively investigated the anti-oral biofilm properties of the Nano-MIX of novel MSN-encapsulated SB (Nano-SB) and Nano-CHX, with reference to our recent findings of Nano-CHX alone against oral biofilms [23]. Meanwhile, the loading and releasing profiles of Nano-SB were characterized, and the capacity of both Nano-SB and SB aqueous extract to penetrate oral mucosa was examined using an ex vivo model of porcine buccal mucosa. Herein, we find the significant synergistic antibacterial effects of the combined usage of Nano-SB and Nano-CHX at 9:1 $(w / w)$ ratio against the mixed oral biofilms, such as S. mutans, F. nucleatum, A. actinomycetemcomitans, and $P$. gingivalis. 


\section{Results}

\subsection{Loading and Releasing Profiles of Nano-SB}

The aqueous extract of SB was swelled and loaded into MSN. The percentage of SB extract loaded to the nanoparticles was determined by thermogravimetric analyses. As shown in Figure 1, the weight loss of Nano-SB was $5.2 \%$ from 100 to $900^{\circ} \mathrm{C}$. As the weight loss of blank nanoparticles was found to be $3.2 \%$ during this range of temperature, the SB loading efficiency was calculated to be $2.0 \%$ after a background subtraction with the blank nanoparticles.
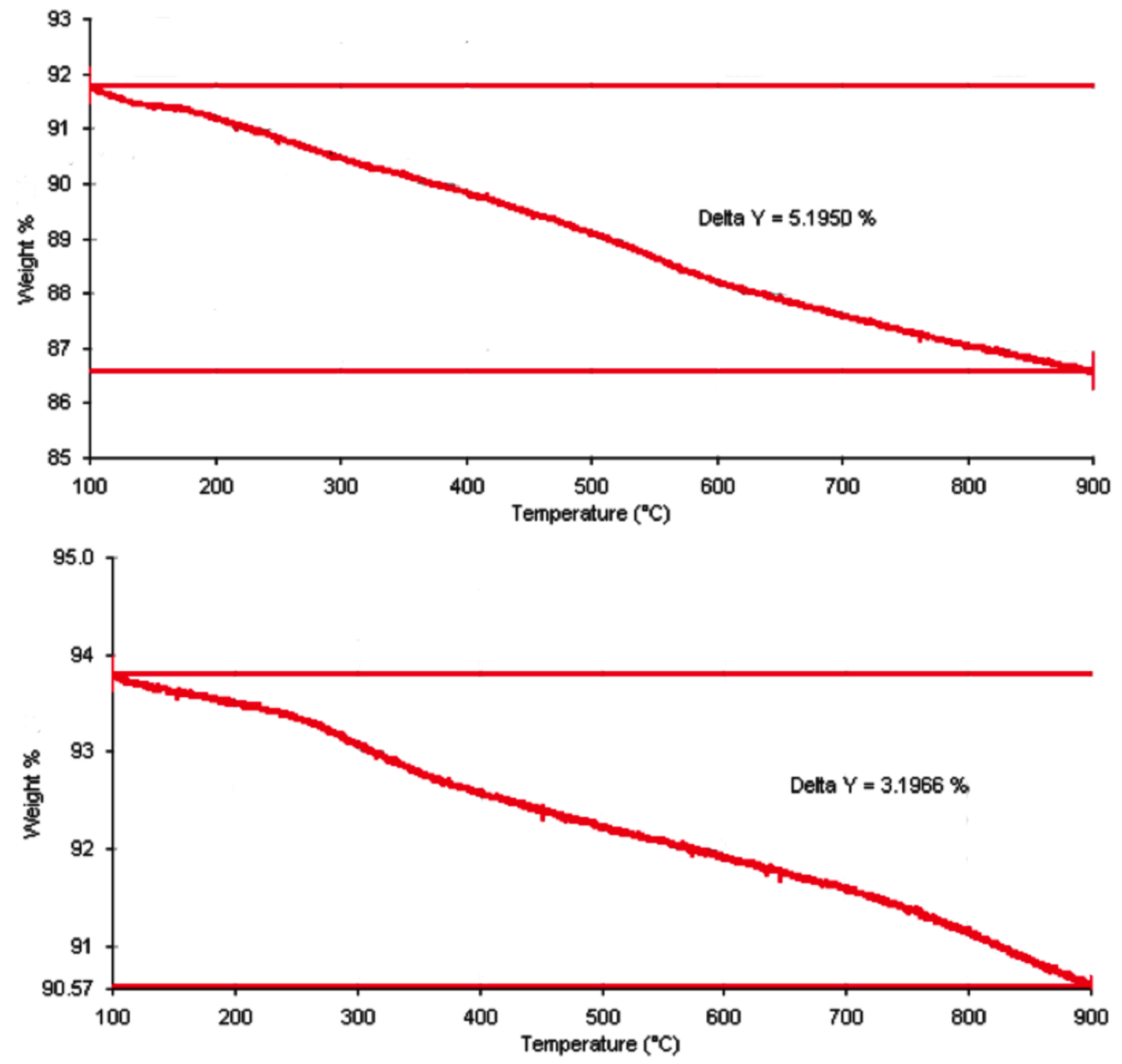

Figure 1. The thermogravimetric analysis on the weight losses of nanoparticle-encapsulated Scutellaria baicalensis (Nano-SB) (5.2\%) (upper) and blank nanoparticles (3.2\%) (lower) between $100{ }^{\circ} \mathrm{C}$ and $900{ }^{\circ} \mathrm{C}$.

The high-performance liquid chromatography (HPLC) analysis of Nano-SB was then performed with reference to baicalin per se and SB aqueous extract. The retention time of baicalin, the biomarker of SB, was assigned at $12.5 \mathrm{~min}$. It was noted that the SB content trapped in MSN could be released in water at $24 \mathrm{~h}$, indicating that Nano-SB was able to release baicalin (Figure 2). 

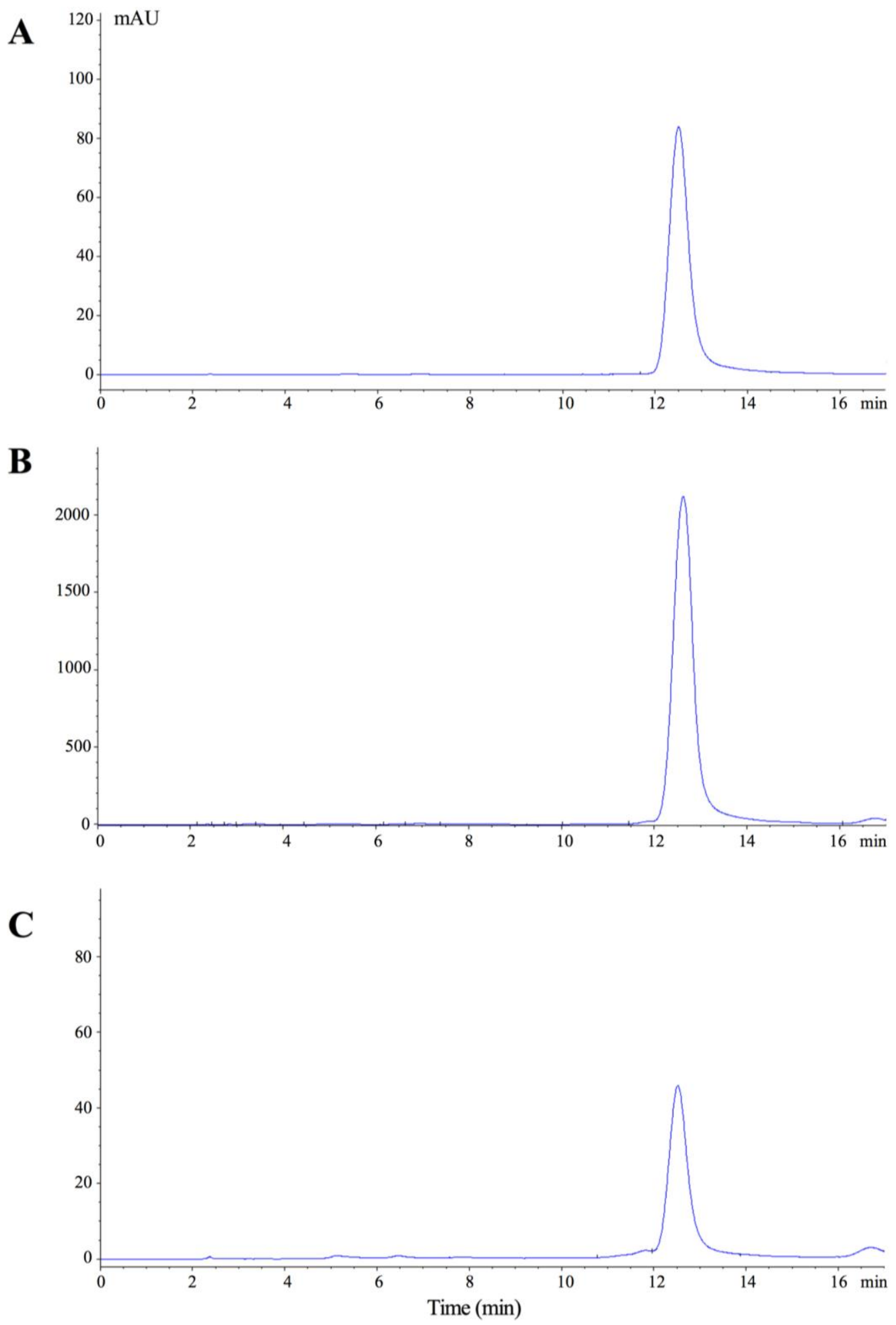

Figure 2. The high-performance liquid chromatography (HPLC) profiles of (A) baicalin; (B) SB aqueous extract; and (C) Nano-SB. Detection was performed at $274 \mathrm{~nm}$, and the retention time of baicalin was assigned at $12.5 \mathrm{~min}$.

\subsection{The Penetration Capacity of Nano-SB through Porcine Buccal Mucosa}

As shown in Table 1, the diffusion experiment found that $14.6 \%$ of baicalin, the bioactive component from the Nano-SB aqueous extract, was retained within the mucosal membrane after 
$2 \mathrm{~h}$ of treatment, with reference to $9.8 \%$ of SB extract. However, after $6 \mathrm{~h}$ of treatment, $46.7 \%$ of baicalin penetrated through the oral mucosal membrane, with reference to $72.5 \%$ of SB extract. Taken together, the total retention rate $(5.8 \%)$ and penetration rate $(46.7 \%)$ of Nano-SB reached $52.5 \%$. Notably, such diffusive and penetrative effects of Nano-SB acted in a relatively slow mode with reference to SB ( $14.6 \%$ vs. $48.8 \%$ at $2 \mathrm{~h}$; and $52.5 \%$ vs. $76.0 \%$ at $6 \mathrm{~h}$ ).

Table 1. Penetration percentage of SB aqueous extract and Nano-SB during the diffusion cell experiment after treatments of $2 \mathrm{~h}$ or $6 \mathrm{~h}$.

\begin{tabular}{ccccc}
\hline $\begin{array}{c}\text { Duration of } \\
\text { Treatment }\end{array}$ & Sample & $\begin{array}{c}\text { Original Amount } \\
\text { of Baicalin }(\boldsymbol{\mu g})\end{array}$ & $\begin{array}{c}\text { Baicalin Retained } \\
\text { within Mucosa (\%) }\end{array}$ & $\begin{array}{c}\text { Baicalin Penetrated to } \\
\text { Receiver Chamber (\%) }\end{array}$ \\
\hline \multirow{2}{*}{$2 \mathrm{~h}$} & SB & 927 & $9.8 \%$ & $39.0 \%$ \\
& Nano-SB & 20 & $14.6 \%$ & $0.0 \%$ \\
\hline \multirow{2}{*}{$6 \mathrm{~h}$} & $\mathrm{SB}$ & 927 & $3.5 \%$ & $72.5 \%$ \\
& Nano-SB & 20 & $5.8 \%$ & $46.7 \%$ \\
\hline
\end{tabular}

\subsection{Antibacterial Effects of Nano-MIX on Planktonic Bacteria and Mono- and Multi-Species Oral Biofilms}

To investigate the synergistic effects of the mixed nanoparticles (Nano-MIX), Nano-SB and Nano-CHX at various ratios were tested in pilot experiments. The 9:1 $(w / w)$ ratio of Nano-SB and Nano-CHX was determined appropriately, and the Nano-MIX was then prepared for the subsequent experiments. The weight percentages of SB and CHX in the Nano-MIX were $1.80 \%$ and $2.02 \%$, respectively. The minimum inhibitory concentration ( $\mathrm{MIC}, \mu \mathrm{g} / \mathrm{mL}$ ) values of Nano-MIX on the planktonic mode and mono-species biofilms of selected oral pathogens with reference to the blank nanoparticles are presented in Table 2. Notably, the Nano-MIX treatment for $24 \mathrm{~h}$ effectively inhibited the mono-species biofilms of $S$. mutans, S. sobrinus, F. nucleatum, and A. actinomycetemcomitans at a low MIC of $50 \mu \mathrm{g} / \mathrm{mL}$. The Nano-MIX also inhibited the mono-species biofilms of Enterococccus (E.) faecalis with a relatively high MIC of $200 \mu \mathrm{g} / \mathrm{mL}$.

Table 2. The minimal inhibitory concentration (MIC, $\mu \mathrm{g} / \mathrm{mL}$ ) of the mixed nanoparticles (Nano-MIX) of Nano-SB and nanoparticle-encapsulated chlorhexidine (Nano-CHX) at 9:1 (w/w) ratio against the planktonic mode and mono-species biofilms of selected oral bacteria at $24 \mathrm{~h}$.

\begin{tabular}{ccc}
\hline Stain & Planktonic Mode & Mono-Species Oral Biofilms \\
\hline S. mutans & 50 & 50 \\
S. sobrinus & 50 & 50 \\
F. nucleatum & 25 & 50 \\
A. actinomycetemcomitans & 50 & 50 \\
E. faecalis & 50 & $200 *$ \\
\hline
\end{tabular}

* Significant difference from the planktonic mode, $p<0.05$.

Moreover, we further examined the preventive action of Nano-MIX on the formation of three selected multi-species biofilms at $24 \mathrm{~h}$ and $48 \mathrm{~h}$. Interestingly, the Nano-MIX had potent antibacterial effects on the mixed-species biofilms of S. mutans, F. nucleatum, and P. gingivalis; S. sobrinus, F. nucleatum, and P. gingivalis; and S. mutans, F. nucleatum, A. actinomycetemcomitans, and P. gingivalis, at low MIC levels of $12.5 \mu \mathrm{g} / \mathrm{mL}(24 \mathrm{~h})$ and $50 \mu \mathrm{g} / \mathrm{mL}(48 \mathrm{~h})$, respectively (Table 3). The anti-biofilm effect on multi-species biofilms of $S$. mutans, F. nucleatum, A. actinomycetemcomitans, and P. gingivalis at $24 \mathrm{~h}$ was further confirmed by both confocal scanning laser microscopy (CLSM) and scanning electron microscopy (SEM). The findings of CLSM (Figure 3A,B) and SEM images (Figure 3C,D) showed that the Nano-MIX treatment markedly affected the multi-species biofilms with few remaining isolated bacterial cells, with reference to the controls treated with blank nanoparticles. 
Table 3. The minimal inhibitory concentration (MIC, $\mu \mathrm{g} / \mathrm{mL}$ ) of the mixed nanoparticles (Nano-MIX) of Nano-SB and nanoparticle-encapsulated chlorhexidine (Nano-CHX) at 9:1 (w/w) ratio against the selected multi-species biofilms of oral bacteria at $24 \mathrm{~h}$ and $48 \mathrm{~h}$.

\begin{tabular}{ccc}
\hline Multi-Species Biofilms & $\mathbf{2 4} \mathbf{~ h}$ & $\mathbf{4 8 ~ h}$ \\
\hline S. mutans, F. nucleatum and P. gingivalis & 12.5 & $50 *$ \\
S. sobrinus, F. nucleatum and P. gingivalis & 12.5 & $50 *$ \\
S. mutans, F. nucleatum, A. actinomycetemcomitans and P. gingivalis & 12.5 & $50 *$ \\
\hline
\end{tabular}

* Significant difference from $24 \mathrm{~h}, p<0.05$.
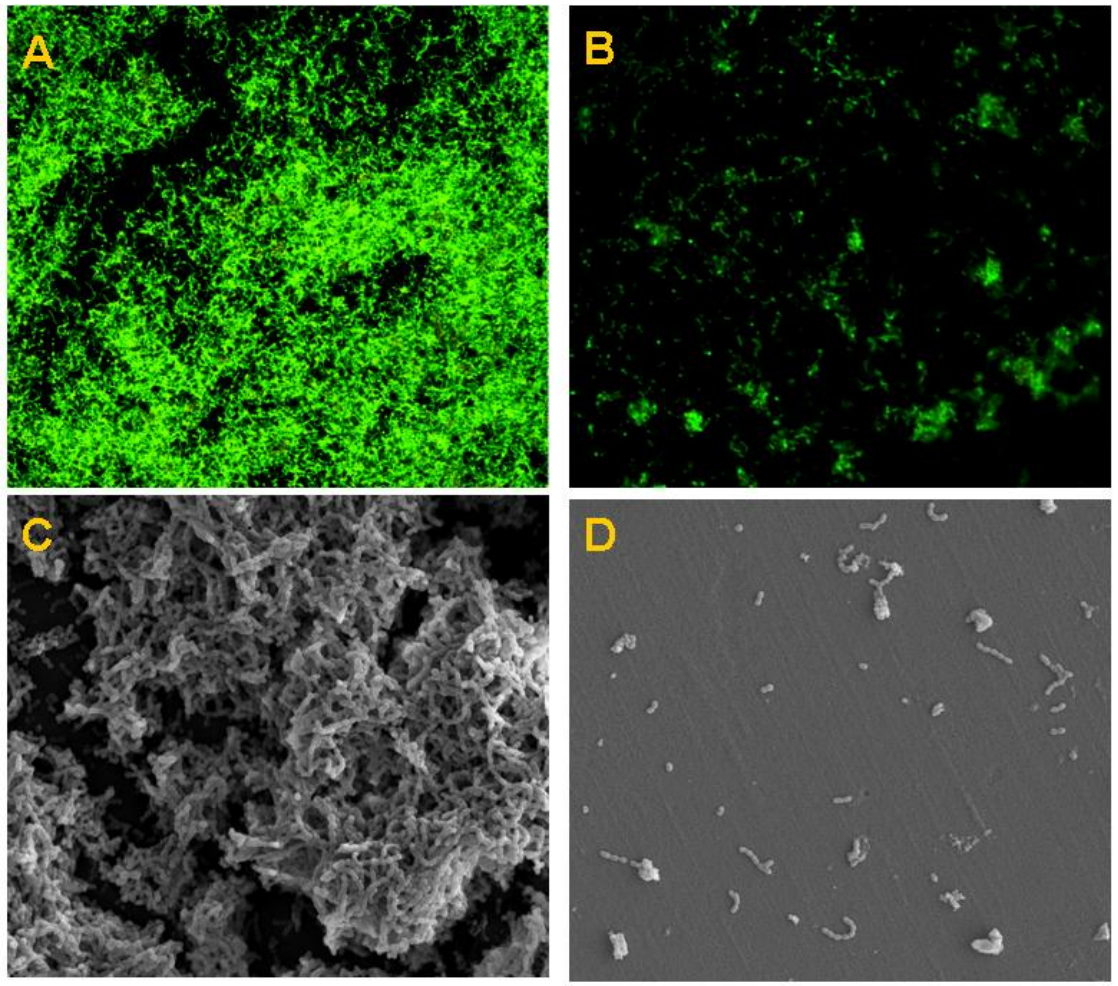

Figure 3. Effect of the Nano-MIX on the multi-species biofilms of S. mutans, F. nucleatum, A. actinomycetemcomitans, and $P$. gingivalis at $24 \mathrm{~h}$. The confocal scanning laser microscopy (CLSM) (A,B) and scanning electron microscopy (SEM) images (C,D) showing comparative antibacterial effects of the Nano-MIX treatment $(\mathbf{B}, \mathbf{D})$ on the mixed-species oral biofilms with reference to the blank nanoparticles $(\mathrm{A}, \mathrm{C})$, respectively.

\section{Discussion}

The characters of the MSN used in the present study have been previously described, presenting an average diameter of $140 \mathrm{~nm}$ with both pore size and volume of about $2.5 \mathrm{~nm}$ and $1.0 \mathrm{~cm}^{3} / \mathrm{g}$, respectively; the $\mathrm{CHX}$ loading efficiency of Nano-CHX is $20.2 \%$ [23]. In the present study, the SB loading efficiency of Nano-SB is $2.0 \%$. The loading efficiency of a substrate towards the mesopores with a fixed diameter $\sim 2 \mathrm{~nm}$ of the silica nanoparticle is governed by the molecular size and shape, polarity of the substrate, and the solvent and method used in the loading process. Moreover, the HPLC analysis reveals that the Nano-SB enables the containment and release of baicalin, the marker of SB. Hence, the nano-encapsulation and releasing process of SB have been effectively undertaken.

$\mathrm{CHX}$ as an essential ingredient in commonly used mouthwash is highly effective for controlling plaque biofilms [6]. However, it has been reported that CHX has some adverse effects like tooth staining and hypersensitive response $[7,8]$. SB or its active species have been loaded to the magnetic 
nanoparticles [31-33] and chitosan nanoparticles [34], and these studies show that the nanoparticles loaded with SB derivatives exhibit an enhanced drug delivery percentage, increased apoptosis of cancer cells, and a reversal of multidrug resistance. The present study investigated for the first time the synergistic effects of Nano-SB and Nano-CHX on selected oral biofilms. Furthermore, our initial proof-of-concept experiment on the penetration of Nano-SB through porcine oral mucosa assessed the active interactions of Nano-SB with oral mucosa tissue and its compatibility for the practical oral applications. Furthermore, a significantly reduced amount of Nano-CHX in the Nano-MIX with Nano-SB and Nano-CHX at 9:1 $(w / w)$ ratio would minimize the unwanted effects of CHX for potential clinical benefits. The findings showed that the Nano-MIX treatment for $24 \mathrm{~h}$ was relatively more effective against the planktonic mode of $S$. sobrinus (MIC, $\mu \mathrm{g} / \mathrm{mL}: 50$ vs. 100), F. nucleatum (25 vs. 50), and E. faecalis (50 vs. 100), with reference to Nano-CHX alone, shown in our recent study [23]. Notably, this trend was also observed against mono-species biofilms, as Nano-MIX had a comparatively lower MIC than the Nano-CHX for S. mutans (50 vs. 100), F. nucleatum (50 vs. 100), A. actinomycetemcomitans (50 vs. 100), and especially S. sobrinus (50 vs. 200). As such, the Nano-MIX exhibited one-fold lower MIC against S. mutans, F. nucleatum, and A. actinomycetemcomitans, and 4-fold lower MIC against S. sobrinus.

Furthermore, Nano-MIX also demonstrated more effective preventive actions against the formation of multi-species biofilms of S. sobrinus, F. nucleatum and P. gingivalis, and S. mutans, F. nucleatum, A. actinomycetemcomitans and $P$. gingivalis after $24 \mathrm{~h}$ treatment, showing one-fold lower MIC with reference to the Nano-CHX alone (12.5 vs. $25 \mu \mathrm{g} / \mathrm{mL})$, respectively [23]. The anti-biofilm effect on S. mutans, F. nucleatum, A. actinomycetemcomitans and P. gingivalis was well supported by the findings of SEM and CLSM images. Similarly, some recent studies have indicated the enhanced antimicrobial activity when pure drugs are incorporated into nanoparticle carriers $[35,36]$. Hence, nanotherapy may bring clinical benefits to the patients suffering from oral biofilm-induced infections and inflammation (e.g. periodontal disease) in the future, although more studies are warranted to translate the current findings into clinical usage.

The present study indicates the enhanced synergistic antimicrobial effects of the Nano-MIX on common oral bacterial biofilms. Further investigation is highly warranted to refine the protocol for optimal antimicrobial effectiveness. It is potentially possible to develop novel nanoparticle-encapsulated multiple agents such as herbal medicine and pure $\mathrm{CHX}$ for better oral and periodontal care.

\section{Materials and Methods}

\subsection{SB Extract and Nano-CHX}

SB aqueous extract was kindly provided by the Hong Kong Premier Concentrated Chinese Herbs Ltd., Kowloon, China, with an extraction yield of 33.3\%. Pure chlorhexidine (base form) and other chemicals were purchased from Sigma-Aldrich (St. Louis, MO, USA). MSN and Nano-CHX were prepared as described in our recent study [23].

\subsection{Thermogravimetric Analysis of SB Loading in MSN}

$\mathrm{SB}$ extract $(50 \mathrm{mg})$ was dissolved in ethanol $(5 \mathrm{~mL})$. The undissolved extracts or compounds were filtered off using a membrane with a pore size of 0.2 micron. The concentration of filtrate was fixed at $7 \mathrm{mg} / \mathrm{mL}$. $50 \mathrm{mg}$ of MSN were then added into $4 \mathrm{~mL}$ of the filtrate. After incubation at room temperature for $24 \mathrm{~h}$, the mixture was centrifuged. The SB aqueous extract-loaded MSNs (Nano-SB) were collected by membrane filtration. Its loading effeminacy was determined with reference to blank MSNs through thermogravimetric analyses by the Perkin Elmer TGA-6 (Waltham, MA, USA), according to an established protocol [20]. 


\subsection{High-Performance Liquid Chromatography (HPLC) Analyses}

The chromatographic profiles of baicalin (a biomark of SB), the SB aqueous extract, and the released Nano-SB were analyzed by a HPLC System, Hewlett Packard Agilent 1100 series equipped with G1329A ALS Autosampler and G1315A Diode Array Detector (Agilent Technologies, Waldbronn, Germany). The solvents were then pre-filtered with the Millipore filter disk $(0.45 \mu \mathrm{m})$ (Millipore, Darmstadt, Germany) and de-gassed. A gradient elution was undertaken using the mobile phases A (methanol) and B (water/phosphoric acid 99.8/0.2 v/v). The elution was carried out with a gradient procedure as follows: $0-8 \mathrm{~min}, 45 \% \mathrm{~B} ; 8-20 \mathrm{~min}$, from $45 \% \mathrm{~B}$ to $48 \% \mathrm{~B}$. The flow rate was set at $1.0 \mathrm{~mL} / \mathrm{min}$, and the detection was made at $278 \mathrm{~nm}$ for baicalin. Ten microliters of each sample were injected into the Ultrasphere ODS C-18 column (Beckman Instrument Inc., Fullerton, CA, USA) after filtration via a filter disk $(0.45 \mu \mathrm{m})$. The baicalin in the SB aqueous extract and released Nano-SB was then identified by comparing the retention times. The system was monitored by a PC with the 32 Karat Software (Beckman Instrument Inc., Fullerton, CA, USA) for data collection, integration, and analysis.

\subsection{Preparation of Porcine Buccal Mucosal Membranes and Diffusion Assays}

Porcine buccal mucosal membranes were used for the in vitro trans-buccal mucosal experiments, to determine the penetration profile of SB and Nano-SB. Fresh porcine heads were obtained from commercial butcher supplier. They were then immediately dissected, and the buccal mucosal membrane was freshly isolated from porcine oral cavity following standard protocol as previously described [25]. In brief, full thickness of the mucosal membrane was cut and liberated from the underlying cartilage using a scalpel. Any adhering subcutaneous fats and tissues were carefully removed. The membrane was then cut into $1.77 \mathrm{~cm}^{2}$ sections and stored at $-80{ }^{\circ} \mathrm{C}$ until further usage.

The diffusion experiments were performed using a diffusion cell system (Taiping Business Mansion, Nanjing, China), consisting of six diffusion cells, diffusion cell drive, and circulating water bath for control of diffusion cells temperature as previously described [37]. Each diffusion cell included a donor and receiving chamber, with a magnetic stirrer at the bottom to ensure thorough mixing of the sample solution at the receiving chamber. The diffusion cell exhibited a diffusion-available surface area of $1.77 \mathrm{~cm}^{2}$. Phosphate buffered saline (PBS) (Invitrogen, San Diego, CA, USA) was used as the diffusion medium, with constant stirring at $600 \mathrm{rpm}$. Temperature was maintained at $37 \pm 0.5^{\circ} \mathrm{C}$ to ensure all membranes was kept at approximately $32{ }^{\circ} \mathrm{C}$ throughout the experiment. Prior to use, all porcine buccal mucosal membranes were soaked in pre-warmed PBS for $5 \mathrm{~min}$ to allow hydration of the membranes. All membranes were then carefully placed on top of each of the diffusion cells, avoiding the presence of air bubbles between the membranes and buffer solution. Donor chambers were placed on top of the membranes, and the samples were applied on top of the membranes. All diffusion cells were clipped tightly to avoid evaporation. To determine the amount of baicalin retained in the membrane, it was extracted by soaking into $2 \mathrm{~mL}$ of methanol followed by sonication for $1 \mathrm{~h}$; for determining the amount of baicalin diffused through the membrane, the receiver medium was withdrawn at determined intervals. All samples were then analyzed by HPLC.

\subsection{Anti-Biofilm Properties of the Nano-MIX (Nano-SB and Nano-CHX at 9:1 w/w)}

Representative oral bacteria including S. mutans (ATCC 35668), S. sobrinus (ATCC 33478), F. nucleatum (ATCC 25586), A. actinomycetemcomitans (ATCC 43718), E. faecalis (ATCC 29212), and P. gingivalis (ATCC 33277), derived from the archival collection at the Centralized Research Laboratory of the Faculty of Dentistry, The University of Hong Kong, were used in the present study. The MIC of planktonic bacteria was assessed, and mono- and mixed-species biofilms were prepared according to our established procedures [23]. The mixed-species biofilms were made under identical experimental conditions and then tested on the anti-biofilm effects of the nanoparticles at $24 \mathrm{~h}$ and $48 \mathrm{~h}$, including (i) S. mutans, F. nucleatum and P. gingivalis; (ii) S. sobrinus, F. nucleatum and P. gingivalis; and (iii) S. mutans, F. nucleatum, A. actinomycetemcomitans and P. gingivalis. In separate experiments, biofilms were formed 
in $1 \times 1 \mathrm{~cm}$ sterilized polystyrene coupons (IWAKI, Tokyo, Japan). The blank silica nanoparticles were employed as the controls. The multi-species biofilm samples of S. mutans, F. nucleatum, A. actinomycetemcomitans and $P$. gingivalis were subjected to further assessments by both SEM (Hitachi, Tokyo, Japan) and CLSM (Olympus, Tokyo, Japan) at $24 \mathrm{~h}$ as previously described [23], in order to confirm the in vitro findngs.

\subsection{Statistical Analysis}

Student's $t$-test or analysis of variance (ANOVA) as appropriate was employed by using the statistical package for the social sciences (SPSS) Statistics (Version 21.0, IBM Corp. Armonk, NY, USA) to determine the statistical significance of MIC between the groups of planktonic and biofilm modes of the bacteria tested, as well as the different time points in the experiments.

Acknowledgments: The authors are grateful to Joanne Yip, Sarah Wong, Suhasini Rajan, and Siu-Fung Lee for their technical assistance in the experiments. This study was supported by the General Research Fund (GRF) from the Hong Kong Research Grants Council (HKU767512M) and the Modern Dental Laboratory/The University of Hong Kong Endowment Fund to L.J.J.

Author Contributions: K.C.-F.L., C.J.S., P.C.L., and L.J.J. conceived and designed the experiments; K.C.-F.L., C.J.S., X.L., C.B.S.L., C.-H.W., K.Y.P., C.W.W., and E.W. performed the experiments; K.C.-F.L., C.J.S., X.L., P.C.L., C.B.S.L., C.-H.W., E.W., and L.J.J. analyzed the data; K.C.-F.L., C.J.S., P.C.L., and L.J.J. contributed reagents/materials/analysis tools; K.C.-F.L., C.J.S., X.L., C.B.S.L., E.W. and L.J.J. wrote the paper.

Conflicts of Interest: All authors declare no competing interests.

\section{Abbreviations}

The following abbreviations are used in this manuscript:

$\begin{array}{ll}\text { SB } & \text { Scutellaria baicalensis } \\ \text { Nano-CHX } & \text { Nanoparticle-encapsulated chlorhexidine } \\ \text { Nano-SB } & \text { Nanoparticle-encapsulated SB } \\ \text { HPLC } & \text { High-performance liquid chromatography } \\ \text { Nano-MIX } & \text { Nano-SB and Nano-CHX } \\ \text { SEM } & \text { Scanning electron microscopy } \\ \text { CSLM } & \text { Confocal scanning laser microscopy } \\ \text { MSN } & \text { Mesoporous silica nanoparticle } \\ \text { PBS } & \text { Phosphate buffered saline } \\ \text { MIC } & \text { Minimum inhibitory concentration }\end{array}$

\section{References}

1. Pihlstrom, B.L.; Michalowicz, B.S.; Johnson, N.W. Periodontal diseases. Lancet 2005, 366, $1809-1820$. [CrossRef]

2. Jin, L.J.; Armitage, G.C.; Klinge, B.; Lang, N.P.; Tonetti, M.; Williams, R.C. Global oral health inequalities: Task group-Periodontal disease. Adv. Dent. Res. 2011, 23, 221-226. [CrossRef] [PubMed]

3. Scannapieco, F.A. Position paper of the american academy of periodontology: Periodontal disease as a potential risk factor for systemic diseases. J. Periodontol. 1998, 69, 841-850. [PubMed]

4. Darveau, R.P. Periodontitis: A polymicrobial disruption of host homeostasis. Nat. Rev. Microbiol. 2010, 8 , 481-490. [CrossRef] [PubMed]

5. Tonetti, M.S.; Chapple, I.L. Biological approaches to the development of novel periodontal therapies-consensus of the seventh european workshop on periodontology. J. Clin. Periodontol. 2011, 38, 114-118. [CrossRef] [PubMed]

6. Baehni, P.C.; Takeuchi, Y. Anti-plaque agents in the prevention of biofilm-associated oral diseases. Oral Dis. 2003, 9, 23-29. [CrossRef] [PubMed]

7. Pemberton, M.N.; Gibson, J. Chlorhexidine and hypersensitivity reactions in dentistry. Br. Dent. J. 2012, 213, 547-550. [CrossRef] [PubMed] 
8. Slot, D.E.; Berchier, C.E.; Addy, M.; Van der Velden, U.; Van der Weijden, G.A. The efficacy of chlorhexidine dentifrice or gel on plaque, clinical parameters of gingival inflammation and tooth discoloration: A systematic review. Int. J. Dent. Hyg. 2014, 12, 25-35. [CrossRef] [PubMed]

9. Lessa, F.C.; Aranha, A.M.; Nogueira, I.; Giro, E.M.; Hebling, J.; Costa, C.A. Toxicity of chlorhexidine on odontoblast-like cells. J. Appl. Oral Sci. 2010, 18, 50-58. [CrossRef] [PubMed]

10. Ikemoto, S.; Sugimura, K.; Yoshida, N.; Yasumoto, R.; Wada, S.; Yamamoto, K.; Kishimoto, T. Antitumor effects of scutellariae radix and its components baicalein, baicalin, and wogonin on bladder cancer cell lines. Urology 2000, 55, 951-955. [CrossRef]

11. Cao, C.F.; Sun, X.P. Herbal medicine for periodontal diseases. Int. Dent. J. 1998, 48, 316-322. [CrossRef] [PubMed]

12. Cai, X.; Li, C.; Du, G.; Cao, Z. Protective effects of baicalin on ligature-induced periodontitis in rats. J. Periodontal Res. 2008, 43, 14-21. [CrossRef] [PubMed]

13. Li, C.Z.; Cao, Z.G.; Yang, R.; Shang, Z.H.; Jin, L.J.; Cobert, E.F. Effects of baicalin on the expression of pro-MMP-1 and MMP-3 in human gingival fibroblasts and periodontal ligament cells. Chin. J. Stomatol. 2004, 39, 197-200.

14. Luo, W.; Wang, C.Y.; Jin, L.J. Baicalin downregulates porphyromonas gingivalis lipopolysaccharide-upregulated IL-6 and IL-8 expression in human oral keratinocytes by negative regulation of TLR signaling. PLoS ONE 2012, 7. [CrossRef] [PubMed]

15. Shen, Y.C.; Chiou, W.F.; Chou, Y.C.; Chen, C.F. Mechanisms in mediating the anti-inflammatory effects of baicalin and baicalein in human leukocytes. Eur. J. Pharmacol. 2003, 465, 171-181. [CrossRef]

16. Wang, G.F.; Wu, Z.F.; Wan, L.; Wang, Q.T.; Chen, F.M. Influence of baicalin on the expression of receptor activator of nuclear factor-kappab ligand in cultured human periodontal ligament cells. Pharmacology 2006, 77, 71-77. [CrossRef] [PubMed]

17. Duan, C.; Matsumura, S.; Kariya, N.; Nishimura, M.; Shimono, T. In vitro antibacterial activities of scutellaria baicalensis georgi against cariogenic bacterial. Pediatr. Dent. J. 2007, 17, 58-64. [CrossRef]

18. Zhenhua, J.; Shuishan, S. Inhibition of Quorum Sensing Activity by Ethanol Extract of Scutellaria baicalensis Georgi. J. Plant Pathol. Microbiol. 2012, 7, 1-4.

19. Jang, E.J.; Cha, S.M.; Choi, S.M.; Cha, J.D. Combination effects of baicalein with antibiotics against oral pathogens. Arch. Oral Biol. 2014, 59, 1233-1241. [CrossRef] [PubMed]

20. Lee, S.F.; Zhu, X.M.; Wang, Y.X.J.; Xuan, S.H.; You, Q.; Chan, W.H.; Wong, C.H.; Wang, F.; Yu, J.C.; Cheng, C.H. Ultrasound, $\mathrm{pH}$, and magnetically responsive crown-ether-coated core/shell nanoparticles as drug encapsulation and release systems. ACS Appl. Mater. Interfaces 2013, 5, 1566-1574. [CrossRef] [PubMed]

21. Wang, Y.X.J.; Zhu, X.M.; Liang, Q.; Cheng, C.H.; Wang, W.; Leung, K.C.F. In vivo chemoembolization and magnetic resonance imaging of liver tumors by using iron oxide nanoshell/doxorubicin/poly(vinyl alcohol) hybrid composites. Angew. Chem. Int. Ed. 2014, 126, 4912-4915. [CrossRef]

22. Wang, D.W.; Zhu, X.M.; Lee, S.F.; Chan, H.M.; Li, H.W.; Kong, S.K.; Jimmy, C.Y.; Cheng, C.H.; Wang, Y.X.J.; Leung, K.C.F. Folate-conjugated $\mathrm{Fe}_{3} \mathrm{O}_{4} @ \mathrm{SiO}_{2} @$ gold nanorods@mesoporous $\mathrm{SiO}_{2}$ hybrid nanomaterial: A theranostic agent for magnetic resonance imaging and photothermal therapy. J. Mater. Chem. B 2013, 1, 2934-2942. [CrossRef]

23. Seneviratne, C.J.; Leung, K.C.; Wong, C.H.; Lee, S.F.; Li, X.; Leung, P.C.; Lau, C.B.; Wat, E.; Jin, L.J. Nanoparticle-encapsulated chlorhexidine against oral bacterial biofilms. PLoS ONE 2014, 9. [CrossRef] [PubMed]

24. Kwon, M.C.; Choi, W.Y.; Seo, Y.C.; Kim, J.S.; Yoon, C.S.; Lim, H.W.; Kim, H.S.; Ahn, J.; Lee, H.Y. Enhancement of the skin-protective activities of centella asiatica l. Urban by a nano-encapsulation process. J. Biotechnol. 2012, 157, 100-106. [CrossRef] [PubMed]

25. Shojaei, A.H. Buccal mucosa as a route for systemic drug delivery: A review. J. Pharm. Pharm. Sci. 1998, 1, 15-30. [PubMed]

26. Galey, W.R.; Lonsdale, H.K.; Nacht, S. The in vitro permeability of skin and buccal mucosa to selected drugs and tritiated water. J. Investig. Dermatol. 1976, 67, 713-717. [CrossRef] [PubMed]

27. Squier, C.; Brogden, K. Human Oral Mucosa: Development, Structure and Function; Wiley-Blackwell: West Sussex, UK, 2011. 
28. Nicolazzo, J.A.; Finnin, B.C. In vivo and in vitro models for assessing drug absorption across the buccal mucosa. In Drug Absorption Studies: In Situ, in Vitro and in Silico Models; Springer: New York, NY, USA, 2008; pp. 89-111.

29. Kulkarni, U.; Mahalingam, R.; Pather, I.; Li, X.; Jasti, B. Porcine buccal mucosa as in vitro model: Effect of biological and experimental variables. J. Pharm. Sci. 2010, 99, 1265-1277. [CrossRef] [PubMed]

30. Wertz, P.W.; Squier, C.A. Cellular and molecular basis of barrier function in oral epithelium. Crit. Rev. Ther. Drug. Carr. Syst. 1991, 8, 237-269.

31. Qing, L.S.; Xiong, J.; Xue, Y.; Liu, Y.M.; Guang, B.; Ding, L.S.; Liao, X. Using bacailin-functionalized magnetic nanoparticles for selectively extracting flavonoids from Rosa chinensis. J. Sep. Sci. 2011, 34, 3240-3245. [CrossRef] [PubMed]

32. Wang, L.; Zhang, H.; Chen, B.; Xia, G.; Wang, S.; Cheng, J.; Shao, Z.; Gao, C.; Bao, W.; Tian, L.; et al.. Effect of magnetic nanoparticles on apoptosis and cell cycle induced by wogonin in Raji cells. Int. J. Nanomed. 2012, 7, 789-798.

33. Cheng, J.; Cheng, L.; Chen, B.; Xia, G.; Gao, C.; Song, H.; Bao, W.; Guo, Q.; Zhang, H.; Wang, X. Effect of magnetic nanoaparticles of $\mathrm{Fe}_{3} \mathrm{O}_{4}$ and wogonin on the reversal of multidrug resistance in K562/A02 cell line. Int. J. Nanomed. 2012, 7, 2843-2852. [CrossRef] [PubMed]

34. Babu, V.N.; Kannan, S. Enhanced delivery of baicalein using cinnamaldehyde cross-linked chitosan nanoparticle inducing apotosis. Int. J. Biol. Macromol. 2012, 51, 1103-1108. [CrossRef] [PubMed]

35. Garapati, C.; Clarke, B.; Zadora, S.; Burney, C.; Cameron, B.D.; Fournier, R.; Baugh, R.F.; Boddu, S.H. Development and characterization of erythrosine nanoparticles with potential for treating sinusitis using photodynamic therapy. Photodiagn. Photodyn. 2015, 12, 9-18. [CrossRef] [PubMed]

36. Horev, B.; Klein, M.I.; Hwang, G.; Li, Y.; Kim, D.; Koo, H.; Benoit, D.S. pH-activated nanoparticles for controlled topical delivery of farnesol to disrupt oral biofilm virulence. ACS Nano 2015, 9, 2390-2404. [CrossRef] [PubMed]

37. Cheng, Y.S.; Ng, K.M.; Wibowo, C. Product design: A transdermal patch containing a traditional chinese medicinal tincture. Ind. Eng. Chem. Res. 2010, 49, 4904-4913. [CrossRef]

(C) 2016 by the authors; licensee MDPI, Basel, Switzerland. This article is an open access article distributed under the terms and conditions of the Creative Commons by Attribution (CC-BY) license (http://creativecommons.org/licenses/by/4.0/). 